\title{
Estimation of photolysis frequencies from TOMS satellite measurements and routine meteorological observations
}

\author{
C. Topaloglou ${ }^{1}$, B. Mayer ${ }^{2}$, S. Kazadzis ${ }^{1,4}$, A. F. Bais ${ }^{1}$, and M. Blumthaler ${ }^{3}$ \\ ${ }^{1}$ Laboratory of Atmospheric Physics, Aristotle University of Thessaloniki, Greece \\ ${ }^{2}$ Deutsches Zentrum für Luft- und Raumfahrt (DLR), Oberpfaffenhofen, Germany \\ ${ }^{3}$ Medical University Innsbruck, Austria \\ ${ }^{4}$ Finnish Meteorological Institute, Helsinki, Finland
}

Received: 10 January 2008 - Revised: 13 May 2008 - Accepted: 27 May 2008 - Published: 21 July 2008

\begin{abstract}
A study on the estimation of $\mathrm{J}\left(\mathrm{O}^{1} \mathrm{D}\right)$ and $\mathrm{J}\left(\mathrm{NO}_{2}\right)$ photolysis frequencies when limited ground based measurements (or even no measurements at all), are available is presented in this work. Photolysis frequencies can be directly measured by chemical actinometry and filter radiometry or can be calculated from actinic flux measurements. In several meteorological stations, none of the methods above are applicable due to the absence of sophisticated instruments such as actinometers, radiometers or spectroradiometers. In this case, it is possible to calculate photolysis frequencies with reasonable uncertainty using either a) standard meteorological observations, such as ozone, cloud coverage and horizontal visibility, available in various ground based stations, as input for a radiative transfer model or b) satellite observations of solar global irradiance available worldwide, in combination with an empirical method for the conversion of irradiance in photolysis frequencies. Both methods can provide photolysis frequencies with a standard deviation between $20 \%$ and $30 \%$. The absolute level of agreement of the retrieved frequencies to those calculated from actual actinic flux measurements, for data from all meteorological conditions, is within $\pm 5 \%$ for $\mathrm{J}\left(\mathrm{O}^{1} \mathrm{D}\right)$ and less than $1 \%$ for $\mathrm{J}\left(\mathrm{NO}_{2}\right)$ for the first method, while for the second method it rises up to $25 \%$ for the case of $\mathrm{J}\left(\mathrm{O}^{1} \mathrm{D}\right)$ and $12 \%$ for $\mathrm{J}\left(\mathrm{NO}_{2}\right)$, reflecting the overestimation of TOMS satellite irradiance when compared to ground based measurements of irradiance for the respective spectral regions. Due to the universality of the methods they can be practically applied to almost any station, thus overcoming problems concerning the availability of instruments measuring photolysis frequencies.
\end{abstract}

Correspondence to: C. Topaloglou

(ctopa@physics.auth.gr)
Keywords. Atmospheric composition and structure (Transmission and scattering of radiation) - Meteorology and atmospheric dynamics (Radiative processes; Instruments and techniques)

\section{Introduction}

Solar ultraviolet radiation drives much of tropospheric and stratospheric chemistry since the photodissociation frequencies of important chemical species are directly related to the incident radiation in this spectral region. For example, the photolysis of $\mathrm{O}_{3}$ and $\mathrm{NO}_{2}$ is driven by ultraviolet radiation which contributes to their decomposition and removal from the atmosphere, as well as the formation of highly reactive radicals, making it a fundamental parameter for atmospheric chemistry studies. Photodissociation of $\mathrm{O}_{3}$ to $\mathrm{O}^{1} \mathrm{D}$ in the presence of water vapour is a key reaction, controlling the oxidation capacity of the atmosphere through the formation of hydroxyl radicals $(\mathrm{OH})$, while $\mathrm{NO}_{2}$ photodissociation influences the removal rate of $\mathrm{NO}$, controls the formation of tropospheric ozone, and is closely related to the radical cycles of $\mathrm{OH}$ and $\mathrm{HO}_{2}$ (Kraus and Hofzumahaus, 1998).

Photolysis frequencies are directly proportional to the actinic flux (Madronich, 1987). The knowledge of this physical quantity is therefore essential for all atmospheric chemistry calculations. However, no systematic measurements of actinic flux are performed worldwide, nor does a widely developed network of stations measuring actinic flux exist, like in the case of horizontal irradiance measurements, most prominent among which, are the networks operating in Canada, the United States, Japan, Europe and New Zealand (WMO, 1998). Regular spectral irradiance measurements

Published by Copernicus Publications on behalf of the European Geosciences Union. 
have started in the late 1980s (Josefsson 1986; Evans et al., 1987; Bais et al., 1993) while some examples of the longest records of spectral UV measurements worldwide are those of Sodankylä, Finland (Masson and Kyrö, 2001), Thessaloniki, Greece (Zerefos et al., 2002), Hohenpeissenberg, Germany (Gantner et al., 2000) and Toronto, Canada starting in 1989 (Kerr and McElroy, 1993). On the other hand, measurements of actinic flux are mainly performed in the framework of field or monitoring campaigns for related scientific projects such as ADMIRA (Actinic Flux Determination from Measurements of Irradiance, http://www.nilu.no/niluweb/services/ admira), INSPECTRO (Influence of Clouds on the Spectral Actinic Flux in the Lower Troposphere) or IPMMI (International Photolysis Frequency Measurement and Model Intercomparison, http://acd.ucar.edu/ cantrell/ipmmi.html).

For this reason, alternative methods have been developed for the retrieval of photolysis frequencies using the existing irradiance measurements from monitoring networks. Several methods include conversion of ground-based (GB) measurements of irradiance to actinic flux, which is then used for the photolysis frequency calculation (Van Weele at al., 1995; Cotté et al., 1997; Kazadzis et al., 2000; Webb et al., 2002b; Kylling et al., 2003; Schallhart et al., 2004) while more recent work introduces the direct calculation of photolysis frequencies from irradiance from empirical relationships (McKenzie et al., 2002; Seroji et al., 2004; Kazadzis et al., 2004; Topaloglou et al., 2005).

The previously mentioned methods can be applied for locations where GB measurements of irradiance are available. However, in order to calculate photolysis frequencies for regions with no radiation measurements satellite irradiance measurements can be used. In the past, satellite measurements of UV backscattered irradiance (e.g. the Total Ozone mapping Spectrometer (TOMS)) were used combined with radiative transfer calculations to derive UV irradiance estimates at the ground (Herman et al., 1999; Krotkov et al., 2001). These estimates are affected by both instrumental errors and modelling uncertainties (Krotkov et al., 2002). Individual comparisons of satellite estimates with GB measurements has shown mainly a positive bias of TOMS, especially during summertime (Herman et al., 1999; Arola et al., 2002; Chubarova et al., 2002; Kazantzidis et al., 2005) and in some cases a negative bias in winter (Kalliskota et al., 2000; Fioletov et al., 2004). According to Herman et al. (1999) and McKenzie et al. (2001), TOMS produces systematically higher UV irradiance values at the northern midlatitudes, while in the Southern Hemisphere a better agreement with surface measurements has been found. These deviations come as a result of a number of sources of uncertainty such as the absolute instrument calibration; different spatial and temporal resolution between GB and satellite measurements, as well as absorption by tropospheric gases and absorbing tropospheric aerosols which are not properly taken into account in the radiative transfer calculations (Fioletov et al., 2002). For the photolysis frequency calculation, actinic flux estimations are required. In the work of Mayer et al. (1998), surface actinic flux was estimated from satellite (TOMS) measurements of ozone and cloud reflectivity at $380 \mathrm{~nm}$. Using this actinic flux retrieved data, global maps of photolysis frequencies were created.

\section{Methodologies and data}

In this work, the photolysis frequencies $\mathrm{J}\left(\mathrm{O}^{1} \mathrm{D}\right)$ and $\mathrm{J}\left(\mathrm{NO}_{2}\right)$ using two different approaches are calculated, when no GB measurements of either actinic flux or irradiance are available:

- The "Satellite Irradiance Method", (SIM): uses global irradiance (irradiance measured on a horizontal surface) derived from TOMS satellite to retrieve $\mathrm{J}\left(\mathrm{O}^{1} \mathrm{D}\right)$ and $\mathrm{J}\left(\mathrm{NO}_{2}\right)$ from an empirical method of converting irradiance to photolysis frequencies.

- The "LibRadTran method", (LM): uses the LibRadtran radiative transfer model to simulate spectral actinic flux (and photolysis frequencies) using as input standard meteorological parameters (total ozone, cloud cover and visibility) which are available at many stations all over the world.

Both methods were tested for an atmosphere with high and complex (Kazadzis et al., 2007; Koukouli et al., 2006) aerosol loading (Thessaloniki, Greece). An assessment of the two methodologies is presented by comparing actual GB measurements of actinic flux and photolysis frequencies to those retrieved from the two methods. As mentioned before, these two approaches hold the advantage of being applicable globally, taking into account the uncertainty of the methods, since satellite measurements are available in numerous locations and radiative transfer model calculations can be used anywhere where certain basic meteorological parameters are available.

2.1 Method 1: the Satellite Irradiance method (SIM method)

TOMS UV products includes surface irradiance estimates at the wavelengths of $305,310,324$, and $380 \mathrm{~nm} \pm 0.25 \mathrm{~nm}$ with a spectral resolution that matches the one of the Brewer instrument (Krotkov et al., 2002, 2005). The TOMS spectral irradiance is converted to $\mathrm{J}\left(\mathrm{O}^{1} \mathrm{D}\right)$ and $\mathrm{J}\left(\mathrm{NO}_{2}\right)$ photolysis frequencies, using the methodology established by Kazadzis et al. (2004) and Topaloglou et al. (2005). To apply this method we selected irradiance at certain wavelengths which are representative of the spectral regions of interest for these two frequencies, namely $305 \mathrm{~nm}$ and $380 \mathrm{~nm}$.

The method presented in the two previous publications (Kazadzis et al., 2004; Topaloglou et al., 2005) is an approach for the retrieval of $\mathrm{J}\left(\mathrm{NO}_{2}\right)$ and $\mathrm{J}\left(\mathrm{O}^{1} \mathrm{D}\right)$ photolysis frequencies from measurements of surface global irradiance. 
The basic idea of this method is the determination of J's as a function of solar zenith angle, by the use of global irradiance and empirical relationships, instead of using actinic flux spectra. Synchronous measurements of actinic flux and global irradiance were used to extract second degree polynomials for the conversion of global irradiance to photolysis frequencies. Indicative values for these polynomial coefficients can be found in Topaloglou et al. (2005). The validity of the method under different atmospheric conditions was also examined by applying the polynomials to another set of actinic flux and global irradiance measurements performed in another location. In this case, comparing $\mathrm{J}$ values extracted from the polynomials to those calculated from actinic flux, showed similar results, demonstrating that the method can also be applied to other measurement sites.

For this work, polynomials were extracted to convert the TOMS irradiance exact wavelengths $\left(305 \mathrm{~nm}\right.$ for $\mathrm{J}\left(\mathrm{O}^{1} \mathrm{D}\right)$ and $380 \mathrm{~nm}$ for $\mathbf{J}\left(\mathrm{NO}_{2}\right)$ ). Results from the method were compared to photolysis frequencies retrieved from GB spectral actinic flux measurements for a four month period (AprilJuly 2003) at Thessaloniki, Greece, during the INSPECTRO campaign.

\subsection{Method 2: the libRadtran method (LM method)}

The aim of this approach is to use meteorological information which is routinely available at many stations worldwide: total ozone (either from GB measurements or satellite observations), cloud cover and horizontal visibility. Spectral actinic flux was calculated with the libRadtran radiative transfer package (Mayer and Kylling, 2005) with the multi-stream DIScrete Ordinates Radiative Transfer equation solver (DISORT) by Stamnes et al. (1988) using 6 streams. Profiles of pressure, temperature and trace gases were used from the mid-latitude summer atmosphere by Anderson et al. (1989). Total ozone was scaled with the TOMS observation for each particular day. A constant surface albedo of 0.06 was assumed. As aerosols profiles we used that from Shettle (1989) as included in libRadtran, where the vertical profiles are parameterized as a function of the horizontal visibility. A well-mixed boundary layer of $1 \mathrm{~km}$ is assumed in this model with a rapid decrease of aerosol extinction above $1 \mathrm{~km}$. For sensitivity tests the rural and maritime profiles were used. The assumptions about the vertical profile and the boundary layer height in particular strongly affect the conversion of horizontal visibility to aerosol optical thickness. As has been shown by Mayer et al. (1997), the parameterization of aerosol via visibility with the methodology explained above improves the accuracy of the simulations considerably. However, the use of optical thickness measurements would further improve the accuracy but limit the spatial coverage, of the LM method. Such measurements can be obtained, for example, using Aerosol Robotic Network (AERONET, http://aeronet.gsfc.nasa.gov) data collected at a number of locations around the world. Concerning clouds, we used only cloud cover from observations, as measurements of cloud optical thickness or other parameters are rare. A fixed water cloud was assumed between 1 and $2 \mathrm{~km}$, with a constant liquid water content of $0.1 \mathrm{gm}^{-3}$ and an effective droplet radius of $10 \mu \mathrm{m}$ which translates to a vertically integrated optical thickness of 15 , essentially constant throughout the whole wavelength range considered. The assumption about the optical thickness is important especially for overcast conditions while the vertical distribution of the cloud has only negligible influence on the result as our sensitivity study showed. The actinic flux $\mathrm{F}$ for broken cloud conditions was calculated with the independent column assumption, repeating the calculation for cloud free $\left(F_{\mathrm{clr}}\right)$ and overcast $\left(F_{\mathrm{cld}}\right)$ conditions:

$F=c F_{\text {cld }}+(1-c) F_{\text {clr }}$

where $c$ is the observed cloud fraction measured in octas. For comparison with observations, the solar zenith angle and Sun-Earth distance for the time of measurement was used in the calculation. The model calculations were performed with high spectral resolution and convoluted with a $1 \mathrm{~nm}$ Full width at half maximum (FWHM) triangular slit function. The GB actinic flux measurements where also standardized to a $1 \mathrm{~nm}$ triangular slit function using, an algorithm for SHIft and quality Control of solar spectral UV measurements developed in the RIVM (SHICRIVM algorithm, Slaper et al., 1995) Institute (National Institute for Public Health and Environment) in Bilthoven, The Netherlands. For the calculation of the photolysis frequencies $\mathrm{J}\left(\mathrm{O}^{1} \mathrm{D}\right)$ and $\mathrm{J}\left(\mathrm{NO}_{2}\right)$ the modeled spectra were weighted with the respective absorption cross sections and quantum yields.

\subsection{Ground-based actinic flux and irradiance measurements}

Actinic flux measurements from $290-500 \mathrm{~nm}$ with a step of $0.5 \mathrm{~nm}$ were performed by the Bentham instrument, using a slit function of $0.92 \mathrm{~nm}$ FWHM, approximately every half hour. The instrument has been used in many UV monitoring campaigns measuring global irradiance or actinic flux or both (Bais et al., 1999; Webb et al., 2002a; Kylling et al., 2003, 2005). Photolysis frequencies from actinic flux spectral measurements $\left(J_{\mathrm{GB}}\right)$ were calculated and were used as a reference in order to evaluate each of the two described method's performances. Global irradiance and actinic flux measurements were alternatively performed during the spectral scan by the same instrument. As a result, almost simultaneous actinic flux and global irradiance measurements are available at each wavelength from which the polynomials of the SIM method were calculated.

The absorption cross section and quantum yield used for the $\mathrm{J}\left(\mathrm{O}^{1} \mathrm{D}\right)$ calculations were those of Daumont et al. (1992) and Matsumi et al. (2001) respectively, while for the $\mathrm{J}\left(\mathrm{NO}_{2}\right)$ calculation both functions used were from DeMore et al. (1997). For the selection of the cloud free days we used the methodology described in Vasaras et al. (2001), 


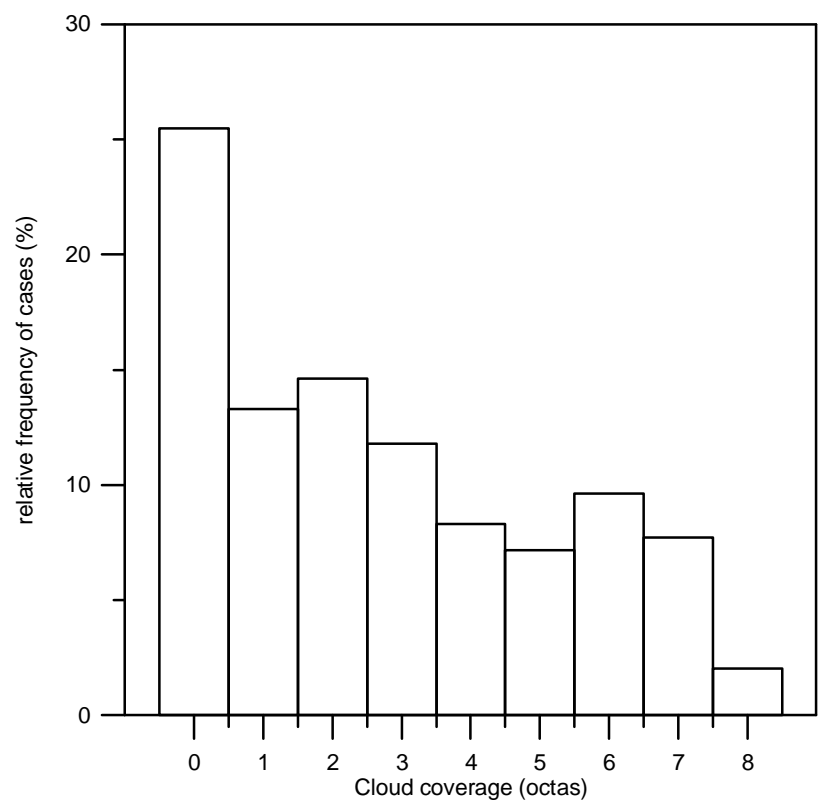

Fig. 1. Relative frequency of appearance for each cloud coverage case, during the Inspectro campaign spectral measurements.

Table 1. Mean ratio and standard deviation between SIM method and GB measurements for irradiance and photolysis frequencies.

\begin{tabular}{lcc}
\hline & $305 \mathrm{~nm}$ & $380 \mathrm{~nm}$ \\
\hline Irradiance TOMS/GB & $1.469 \pm 0.330$ & $1.166 \pm 0.245$ \\
& $\mathrm{~J}\left(\mathrm{O}^{1} \mathrm{D}\right)$ & $\mathrm{J}\left(\mathrm{NO}_{2}\right)$ \\
Photolysis freq. SIM/GB & $1.266 \pm 0.261$ & $1.128 \pm 0.207$ \\
\hline
\end{tabular}

which is based on the variability of the measurements from a collocated pyranometer. In addition, meteorological observations of sky cloud coverage (in octas) were used. The cloud observations correspond to the spectroradiometer's time of the spectral measurement and frequency of each cloud coverage case appearance as a percentage of the total number of the observations is shown in Fig. 1.

\section{Comparison of measurements and methods}

3.1 Comparison of Satellite Input Method and Ground Based photolysis frequencies

As already mentioned in the previous section, the time period examined was April to July 2003. In order to make the comparison between TOMS and the GB instrument, the measurements of TOMS closest in time to those performed on the ground were used. First, we show the comparison between satellite irradiance and GB irradiance measured by the Bentham spectrophotometer both standardized to a 0.55 tri-
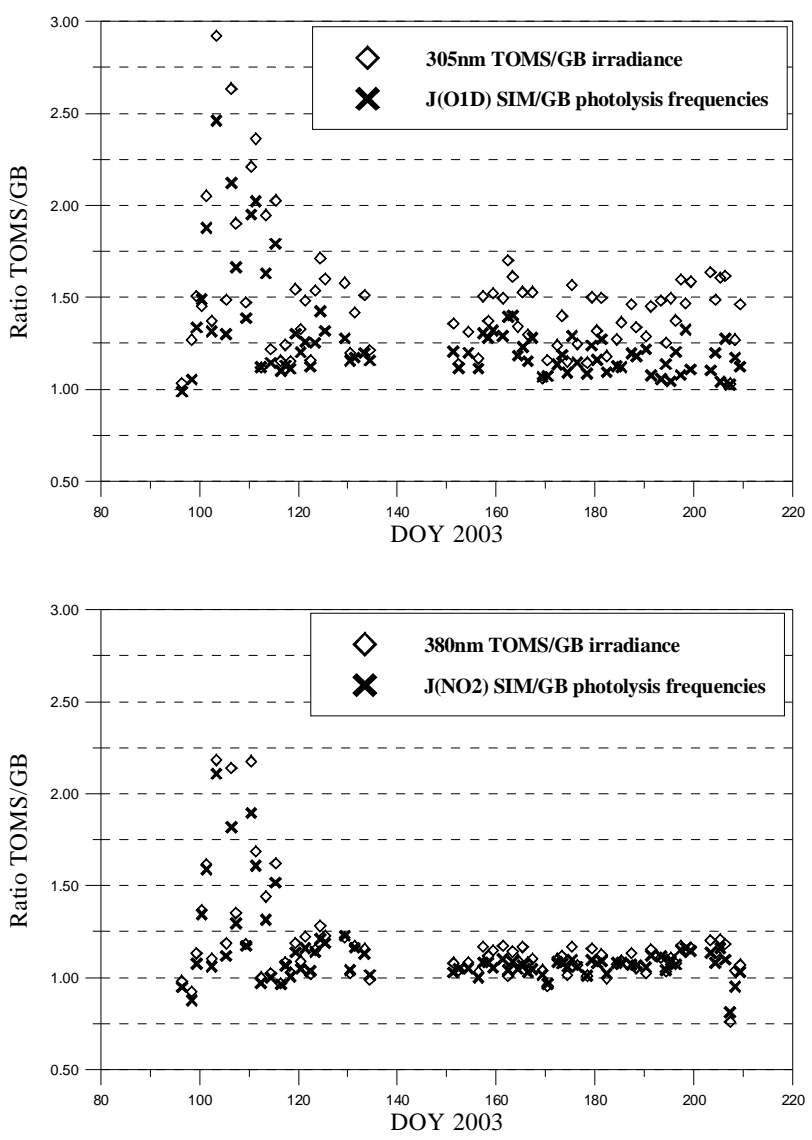

Fig. 2. Ratio of TOMS/GB measurements of irradiance and SIM/GB photolysis frequencies, $305 \mathrm{~nm}$ and $\mathrm{J}\left(\mathrm{O}^{1} \mathrm{D}\right)$ (upper) and $380 \mathrm{~nm}$ and $\mathrm{J}\left(\mathrm{NO}_{2}\right)$ (lower).

angular slit function, followed by the comparison of the derived photolysis frequencies $\left(J_{\mathrm{SIM}}\right)$. The comparison of the two wavelengths ( 305 and $380 \mathrm{~nm}$ ) between TOMS and GB measurements as well as the $J_{\mathrm{SIM}} / J_{\mathrm{GB}}$ photolysis frequency comparison are shown in Fig. 2. The results are summarized in Table 1.

Before applying the method to TOMS (or other) data, calculations were performed concerning the uncertainty of the method itself. To achieve that, we used irradiance measurements from the Bentham instrument simultaneously performed with those of actinic flux to derive photolysis by using the empirical method. In this way there are no uncertainties introduced neither by synchronization of the measurements nor by possible instrument differences. The ratio of J's calculated from the method using Bentham's irradiance over $\mathrm{J}$ 's from actinic flux is $0.98 \pm 0.07$ for $\mathrm{J}\left(\mathrm{O}^{1} \mathrm{D}\right)$ and $0.99 \pm 0.08$ for $\mathrm{J}\left(\mathrm{NO}_{2}\right)$ and they refer solely to the polynomial method performance.

The agreement between SIM/GB ratio of $\mathrm{J}\left(\mathrm{NO}_{2}\right)$ and TOMS/GB ratio for $380 \mathrm{~nm}$ irradiance is very similar, showing that the irradiance comparison is reflected on the 
photolysis frequencies. Most of the large discrepancies shown in Fig. 2 are due to cloud variability. That is because TOMS reflectivity represents the cloud fraction per satellite grid (pixel) and no information about the real direct sun attenuation is taken into account when TOMS irradiance is retrieved. More detailed analysis of the cloud impacts can be found in Sect. 3.4. Regarding the $305 \mathrm{~nm}-\mathrm{J}\left(\mathrm{O}^{1} \mathrm{D}\right)$ correlation, we observe that the photolysis frequency comparison is significantly improved compared to that of the single wavelength irradiance used in the method, both in terms of mean ratio and standard deviation. This can be explained by the fact that the empirical (SIM) method used to retrieve the photolysis frequencies from irradiance data uses only the TOMS measurement at $305 \mathrm{~nm}$ which, as demonstrated in Fig. 2, shows an overestimation compared to the GB irradiance measurements. However the effective wavelengths for the $\mathrm{O}_{3}$ photolysis frequencies is higher than $305 \mathrm{~nm}$ and the calculation of $\mathrm{J}\left(\mathrm{O}^{1} \mathrm{D}\right)$ from ground-based actinic flux measurements, applies the proper spectral weighting according to the absorption cross section and the quantum yield used. In addition, the application of the polynomial functions used for the SIM photolysis frequencies calculation from the irradiance measurements is partly responsible for the above fact. Sensitivity studies have shown that changes in the order of $\pm 5 \%$ in the $305 \mathrm{~nm}$ irradiance input of the polynomial functions resulted in a $2.5 \%$ deviation in the retrieved $\mathrm{J}\left(\mathrm{O}^{1} \mathrm{D}\right)$ and $3.5 \%$ for the case of $\mathrm{J}\left(\mathrm{NO}_{2}\right)$, demonstrating that the SIM method produces smaller discrepancies between the retrieved and GB photolysis frequencies than those between TOMS and GB irradiance.

\subsection{Comparison of LibRadTran method and ground based measurements}

\subsubsection{Actinic flux comparison}

First, a comparison of the actinic flux between the model calculation and the GB measurements for the spectral range of $295-420 \mathrm{~nm}$ is shown in Fig. 3. The data set is provided from the INSPECTRO monitoring campaign. As mentioned before, the model calculations use the actual solar zenith angle of each measurement as input together with TOMS total column ozone, horizontal visibility, and cloud cover.

The actinic flux from the model calculation $\left(F_{\mathrm{LM}}\right)$ is compared to the synchronous GB measurements of actinic flux $\left(F_{\mathrm{GB}}\right)$. The ratio of $F_{\mathrm{LM}} / F_{\mathrm{GB}}$ is shown as a function of wavelength for two aerosol type model input cases, one of maritime aerosols (left) and another of rural aerosols (right).

The mean ratios calculated from $\sim 2400$ spectral measurements, show a quite good agreement for the spectral region of 300-420 nm especially when the maritime aerosol type is used. No significant differences to these mean values were found comparing clear sky (900 spectra) to all sky conditions. The absolute level of agreement is influenced by both the choice of aerosol mode used in the model (maritime or
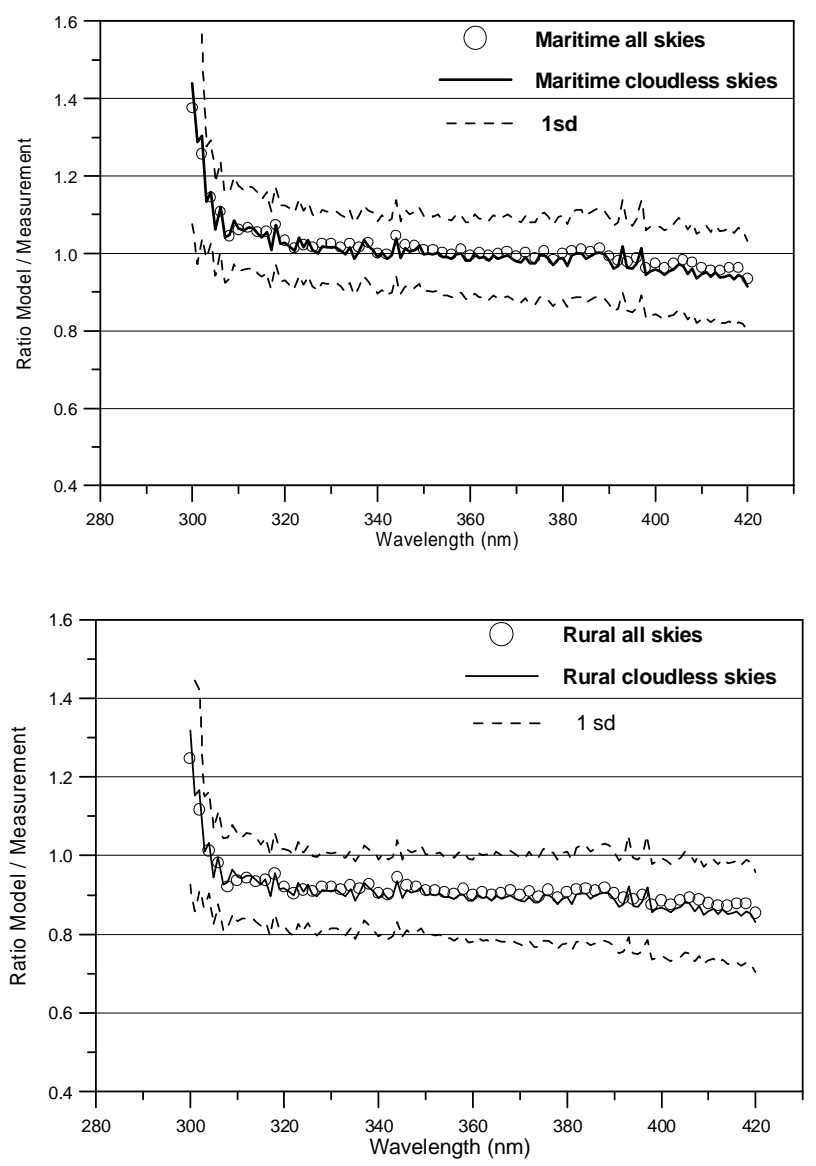

Fig. 3. Ratio of model estimated over measured actinic flux using maritime (upper) and rural (lower) aerosol type as model input. Cloudless cases wavelength averages are shown (continuous line) while all cases are shown in circles. Also the mean value $( \pm 1 \sigma)$ standard deviation for cloud free cases is shown in dashed lines.

rural) as well as the RTM conversion of horizontal visibility to aerosol optical depth. The wavelength dependence of the ratios is in the order of $10 \%$ and $8 \%$ for maritime and rural cases, respectively. Most of this variation is observed for wavelengths larger than $380 \mathrm{~nm}$. Such deviations could arise from the instrument calibration and primary standard lamp sources in use. The ratios for wavelengths lower than $305 \mathrm{~nm}$ show a systematic overestimation of the model calculated actinic flux. The use of a single ozone value provided from TOMS data could be considered as a possible reason for such deviations. In addition, the uncertainty of the GB measured actinic flux is high in the specific wavelength range. The standard deviation of these ratios significantly increases when all sky cases are taken into account. In Table 2 below, the mean ratios and standard deviation for two wavelengths $(305 \mathrm{~nm}$ and $380 \mathrm{~nm})$ are presented. The wavelength selection of 305 and $380 \mathrm{~nm}$ is related to their maximum contribution (compared to the other wavelengths) to the $\mathrm{O}_{3}$ and $\mathrm{NO}_{2}$ photolysis frequencies, respectively. 
Table 2. Mean ratio and standard deviation of model estimated actinic flux at 305 and $380 \mathrm{~nm}$ for two aerosols types over measured actinic flux for $\mathrm{sza}<85^{\circ}$.

\begin{tabular}{lcc}
\hline All data & $305 \mathrm{~nm}$ & $380 \mathrm{~nm}$ \\
\hline Rural aerosols & $0.93 \pm 0.31$ & $0.90 \pm 0.32$ \\
Maritime aerosols & $1.05 \pm 0.32$ & $0.99 \pm 0.32$ \\
Cloud free data (0 octas) & $305 \mathrm{~nm}$ & $380 \mathrm{~nm}$ \\
Rural aerosols & $0.95 \pm 0.12$ & $0.89 \pm 0.11$ \\
Maritime aerosols & $1.07 \pm 0.12$ & $0.99 \pm 0.10$ \\
\hline
\end{tabular}

Table 3. Mean ratio (and standard deviation) of model estimated $\mathrm{J}\left(\mathrm{O}^{1} \mathrm{D}\right)$ and $\mathrm{J}\left(\mathrm{NO}_{2}\right)$ for two types of aerosols over photolysis frequencies from measurements of actinic flux $\left(\mathrm{sza}<85^{\circ}\right)$.

\begin{tabular}{lcc}
\hline All data & $\mathrm{J}\left(\mathrm{O}^{1} \mathrm{D}\right)$ & $\mathrm{J}\left(\mathrm{NO}_{2}\right)$ \\
\hline Rural aerosols & $0.943 \pm 0.301$ & $0.908 \pm 0.331$ \\
Maritime aerosols & $1.066 \pm 0.316$ & $1.002 \pm 0.331$ \\
Cloud free data $(0 / 8)$ & $\mathrm{J}\left(\mathrm{O}^{1} \mathrm{D}\right)$ & $\mathrm{J}\left(\mathrm{NO}_{2}\right)$ \\
Rural aerosols & $0.953 \pm 0.125$ & $0.897 \pm 0.118$ \\
Maritime aerosols & $1.078 \pm 0.123$ & $1.002 \pm 0.109$ \\
\hline
\end{tabular}

The general agreement is within acceptable limits for the two aerosol approaches. More specifically, the ratio between modelled and measured actinic flux is within $\pm 7 \%$ around unity for both aerosol approaches with a standard deviation of $\sim 30 \%$ for $305 \mathrm{~nm}$ and within 0.9 and 0.99 with the same standard deviation for $380 \mathrm{~nm}$. The standard deviation of the cloud free skies dataset is substantially reduced compared to the all-conditions data set, namely from $30 \%$ to $10 \%(1 \sigma)$. Rural aerosol model input parameters lead to a general underestimation of the actinic flux compared to the spectroradiometer's measurements especially for larger solar zenith angles. For solar zenith angles up to $50^{\circ}$, we observe a small deviation and the ratio is around unity, higher for maritime and lower for rural aerosol types, suggesting that the actual aerosol in Thessaloniki might be best described by a mixture of both. In other words, differences between the approximate input values of the model and the actual atmospheric parameters will produce higher deviations between modelled and measured actinic flux.

\subsubsection{Photolysis frequency comparison between model and ground-based measurements}

The photolysis frequency values from the model calculation are compared to the $J_{\mathrm{GB}}$ values derived from the GB measurements of actinic flux. In Fig. 4, the ratio of $J_{\mathrm{LM}} / J_{\mathrm{GB}}$ is shown, for the two photolysis frequencies $\mathrm{J}\left(\mathrm{O}^{1} \mathrm{D}\right)$ and $\mathrm{J}\left(\mathrm{NO}_{2}\right)$ for all (upper panel) and cloud free (lower panel) sky conditions. In Table 3 below, the mean ratios and standard
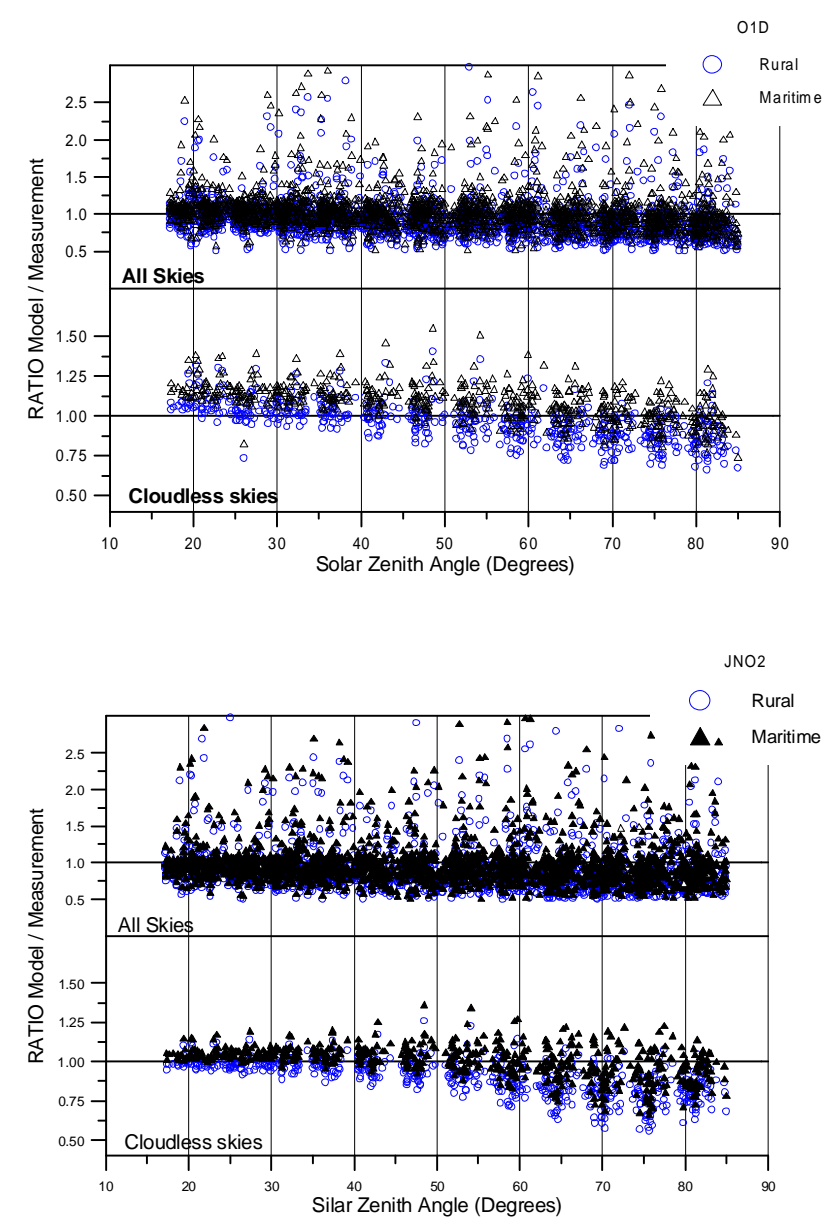

Fig. 4. Ratio of model estimated over measured photolysis frequencies, $\mathrm{J}\left(\mathrm{O}^{1} \mathrm{D}\right)$ (upper) and $\mathrm{J}\left(\mathrm{NO}_{2}\right)$ (lower), as a function of solar zenith angle for cloud free data and all data for two aerosol types used in the model calculations.

deviation are presented. The ratio diverges more from unity and the standard deviation increases with solar zenith angle. Since the model uses approximations for both the aerosol optical depth (derived from horizontal visibility) and the single scattering albedo, it is expected that higher deviations will be observed for higher solar zenith angles due to longer optical path. In addition, $\mathrm{J}\left(\mathrm{NO}_{2}\right)$ ratios show smaller variability at high solar zenith angles than the one of $\mathrm{J}\left(\mathrm{O}^{1} \mathrm{D}\right)$ due to the fact that the latest is more affected from aerosol input uncertainties.

The comparison of both $\mathrm{J}\left(\mathrm{O}^{1} \mathrm{D}\right)$ and $\mathrm{J}\left(\mathrm{NO}_{2}\right)$ is quite good since the ratio of modelled to measured frequencies is close to unity especially for maritime aerosol type. These results follow the same pattern with the comparison of actinic flux wavelengths shown in Fig. 3. These two photolysis frequencies can be satisfactorily reproduced by the LM model calculation method with a standard deviation of $\sim 30 \%$ for all data and $\sim 12 \%$ for cloud free data. 
A main source of uncertainty of the model calculation is the fact that there is no information in the model input about the sun being visible or not. The model scales both the direct and diffuse component of the radiation according to the cloud cover. The effect of these approximations may lead to differences up to $\pm 25 \%$ around unity in the $J_{\mathrm{LM}} / J_{\mathrm{GB}}$ ratios for the same cloud cover. This is demonstrated from examining case studies for both low (3/8) and high (7/8) cloud cover. In addition, since the model uses hourly cloud cover values and a constant cloud optical depth of 15 , an additional uncertainty may be introduced in the case of variable cloudiness within this hour. Finally, the assumption of the boundary layer height determines the conversion of horizontal visibility to aerosol optical depth which may introduce additional uncertainty sources depending on the variability of the aerosol profiles over Thessaloniki area for the period analyzed.

Finally, it should be noted that the main purpose of the model calculations using minimum input parameters was to derive a methodology that can be applied to other stations that have the availability of such - standard meteorological information - products.

\subsection{Comparison of the two methods}

In order to compare the results of the two methods, the ratio of the photolysis frequencies from the two approaches (LM derived and SIM derived) versus the GB Js will be presented in the next few graphs as an addition to the analysis of the previous sections. The results of the two methods are presented together, including only GB measurements and model calculations that are performed in the same time period of the day that TOMS overpasses Thessaloniki (between 08:30 and 10:00 UT). $J_{\text {meth }}$ refer to the photolysis frequencies derived by any of the two methods ( $J_{\text {SIM }}$ for the satellite method and $J_{\mathrm{LM}}$ for the model calculation) while $J_{\mathrm{GB}}$ refer to those calculate by GB measured actinic flux.

As shown in Fig. 5, the results are quite similar for the two approaches. The absolute level of agreement between $J_{\text {SIM }}$ and the $J_{\mathrm{GB}}$ photolysis frequencies is slightly higher compared to the $J_{\mathrm{LM}} / J_{\mathrm{GB}}$ ratio, especially for the case of $\mathrm{J}\left(\mathrm{O}^{1} \mathrm{D}\right)$, while the standard deviation is approximately the same. The difference in the absolute level between the two methods reflects the overestimation of TOMS when compared to the GB measurements of irradiance, as shown in Fig. 2 and Table 1, a feature which is more pronounced for the $305 \mathrm{~nm}$ than the $380 \mathrm{~nm}$. This explains the better agreement of the two methods for the $\mathrm{J}\left(\mathrm{NO}_{2}\right)$ case. To improve the results further more, we show below the same comparison including low cloud data ( $0-3$ octas).

The comparison of the results from the two methods for the measurements performed during the satellite's overpass (08:30-10:00 UT) are shown below, in Table 4, for all data and low cloud data (0-3/8): The SIM method tends to overestimate the photolysis frequencies, especially the $\mathrm{J}\left(\mathrm{O}^{1} \mathrm{D}\right)$ up
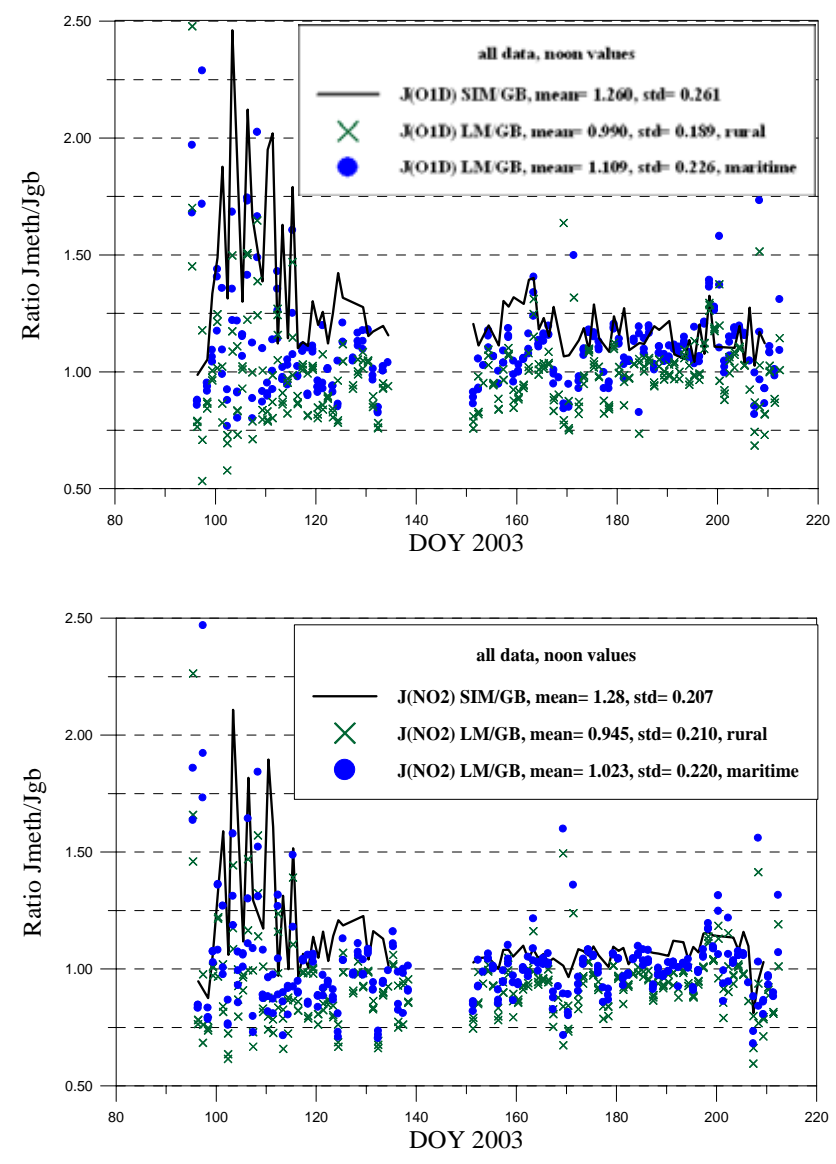

Fig. 5. Ratio of $\mathrm{J}\left(\mathrm{O}^{1} \mathrm{D}\right)$ and $\mathrm{J}\left(\mathrm{NO}_{2}\right)$ estimated by the two methods over GB retrieved from actinic flux. Continuous line shows the ratio of $J_{\mathrm{SIM}} / J_{\mathrm{GB}}$ while symbols the ratio $J_{\mathrm{LM}} / J_{\mathrm{GB}}$ (circles for maritime and crosses for rural aerosols).

to $27 \%$, while the model calculation results are rather satisfactory for both $\mathrm{J}\left(\mathrm{O}^{1} \mathrm{D}\right)$ and $\mathrm{J}\left(\mathrm{NO}_{2}\right)$ with slight variations of the ratio depending on the aerosol type used. Both methods show similar standard deviation in the order of $20-25 \%$. As observed from the tables, the absolute agreement of the photolysis frequencies remains in the case of cloud free data however the standard deviation is reduced substantially compared to the whole data set and is narrowed to a level of 4$9 \%$.

\subsection{Comparison of methods versus cloud cover}

Following, the ratios between photolysis frequencies calculated by the two methods versus those from GB actinic flux are shown as a function of observed cloud cover. As expected, the standard deviation of the ratio increases with cloud cover for both methods. For the LM method, the mean ratio and standard deviation of the measurements for each cloud cover group is shown, while for the SIM ratios, the ratio is shown for each measurement separately due to limited number of measurements for each cloud cover group. The 
Table 4. Mean ratio and standard deviation of photolysis frequencies derived from the two methods, $J_{\mathrm{TOMS}}$ and $J_{\text {model }}$, compared to $J_{\mathrm{GB}}$ from GB actinic flux for all data and low cloud fraction cases.

\begin{tabular}{lccc}
\hline All data & Model maritime/GB & Model rural/GB & TOMS/GB \\
\hline $\mathrm{J}\left(\mathrm{O}^{1} \mathrm{D}\right)$ & $1.109 \pm 0.226$ & $0.99 \pm 0.189$ & $1.26 \pm 0.261$ \\
$\mathrm{~J}\left(\mathrm{NO}_{2}\right)$ & $1.023 \pm 0.22$ & $0.945 \pm 0.21$ & $1.128 \pm 0.207$ \\
Low Cloud Fraction data (0 to 3/8) & & & \\
$\mathrm{J}\left(\mathrm{O}^{1} \mathrm{D}\right)$ & $1.07 \pm 0.101$ & $0.977 \pm 0.104$ & $1.18 \pm 0.093$ \\
$\mathrm{~J}\left(\mathrm{NO}_{2}\right)$ & $0.994 \pm 0.108$ & $0.930 \pm 0.107$ & $1.072 \pm 0.06$ \\
\hline
\end{tabular}
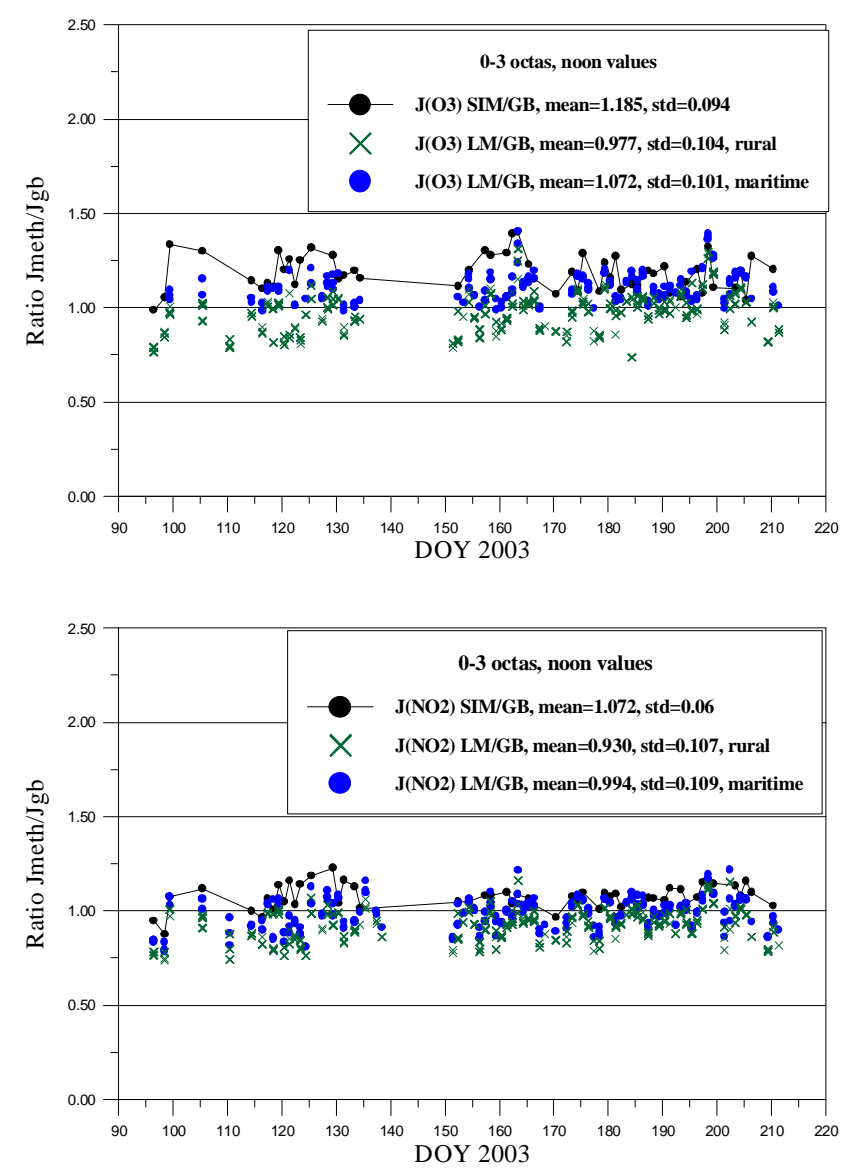

Fig. 6. Ratio of calculated to measured photolysis frequencies for low cloud cover conditions ( $0-3$ octas). Crosses and diamonds show the ratio of the model calculated Js over GB ones, while full circles the ratio of TOMS derived frequencies over ground based Js.

results described above are shown in Fig. 7 for $\mathrm{J}\left(\mathrm{O}^{1} \mathrm{D}\right)$ and are similar for the $\mathrm{J}\left(\mathrm{NO}_{2}\right)$ case.

The behaviour of the model to GB ratio between model and GB photolysis frequencies is a result of the approximation the model uses to scale the radiation according to cloud cover as mentioned previously. Previous work has shown that the model approximation tends to underestimate radia-

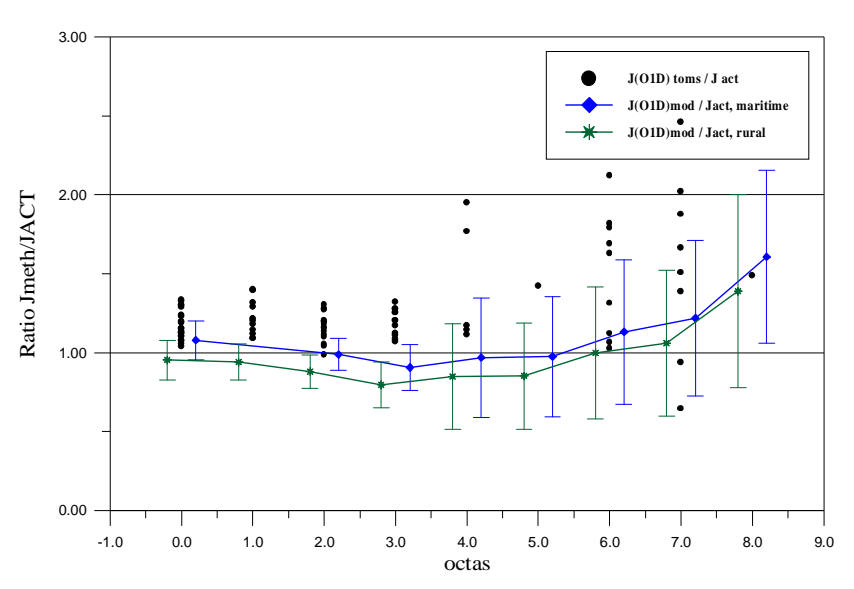

Fig. 7. Ratio of estimated over GB photolysis frequencies as a function of cloud cover for $\mathrm{J}\left(\mathrm{O}^{1} \mathrm{D}\right)$.

tion for low cloud cover and overestimate it for high cloud cover since it can not include information about the visibility of the solar disk. The direct component is reduced in the model calculations according to the cloud cover. This leads to lower direct radiation for cases of low cloud coverage ( 2 or 3 octas) of the sky where there is high probability that the sun is completely visible and higher direct radiation is measured by the instrument.

\section{Conclusions}

In this work we present two methods to estimate the photolysis frequencies of $\mathrm{NO}_{2}$ and $\mathrm{O}^{1} \mathrm{D}$ either from satellite data alone or from basic input parameters which are available at many stations. From the comparison of photolysis frequencies retrieved from these methods to photolysis frequencies calculated from ground-based measurements of actinic flux we conclude to the following results:

- Actinic flux wavelengths 305 and $380 \mathrm{~nm}$ can be reproduced satisfactorily by the libRadtran model with an uncertainty of $30 \%$ for all cases and $12 \%$ for cloud free cases. The absolute level of agreement for $\mathrm{J}\left(\mathrm{NO}_{2}\right)$ ratio varies between 0.9 and 1 depending on the aerosol 
type used in the model calculations, while $\mathrm{J}\left(\mathrm{O}^{1} \mathrm{D}\right)$ estimation ratio varies between 0.95 for rural, and 1.05 for maritime aerosols. For cloud free cases the ratios remain approximately same for each case while the standard deviation falls to $12 \%$ for both $\mathrm{J}\left(\mathrm{O}^{1} \mathrm{D}\right)$ and $\mathrm{J}\left(\mathrm{NO}_{2}\right)$ similar to the actinic flux comparison.

- SIM method results to a ratio of 1.25 for the $\mathrm{J}\left(\mathrm{O}^{1} \mathrm{D}\right)$ comparison and 1.13 for $\mathrm{J}\left(\mathrm{NO}_{2}\right)$ with the standard deviation around $25 \%$. Comparing the results to those of the model calculation, only for overpass time measurements, the variation of the ratio remains similar, however the ratios are shifted towards higher values and the standard deviation decreases. More specifically, $\mathrm{J}\left(\mathrm{NO}_{2}\right)$ ratio of calculated to GB photolysis frequencies varies from 0.94 to 1.02 depending on aerosol type, with standard deviation $20 \%$ for all conditions, for cloud free noon values and for $\mathrm{J}\left(\mathrm{O}^{1} \mathrm{D}\right)$ from 0.99 to 1.1 with the same deviation.

- For completely cloud free cases (0/8), the mean ratios of calculated $\mathrm{J}\left(\mathrm{O}^{1} \mathrm{D}\right)$ and $\mathrm{J}\left(\mathrm{NO}_{2}\right)$ are shifted to slightly higher values for both aerosol approximations, but the standard deviation drops to $3-7 \%$.

- From the study of the ratios versus cloud cover, we observe ratios lower than 1 for cloud cover up to $4 / 8$, while for very high cloud cover the ratios are above unity. The behavior of the ratio is a result of the model approximation for scaling the radiation according to the cloud cover. From previous work (INSPECTRO meeting in Rome, 2005) we have seen that the model approximation tends to underestimate radiation for low cloud cover and overestimates it for high cloud cover.

In the absence of routine actinic flux measurements due to the special configured optics required, the development of alternative methods to retrieve photolysis frequency values for $\mathrm{NO}_{2}$ and $\mathrm{O}_{3}$ can be very useful for atmospheric chemistry studies, since these quantities are important input parameters for tropospheric chemistry models. Satellite global irradiance measurements are globally available since the start of 1980s and also basic meteorological parameters used for the LM method are also easy to find worldwide. Therefore, the retrieval of photolysis rate values from global irradiance measurements allows the reproduction of extensive time series of photolysis rates for nitrogen dioxide and ozone, within reasonable uncertainty. These photolysis retrieval results absolute differences compared to ground level data are in the same order of magnitude with the compared satellite to GB irradiance.

As shown in Topaloglou et al. (2005), the methodology of the conversion of irradiance to photolysis frequencies can be applied at other locations than Thessaloniki. In addition, the LM method can also be applied globally. In the latter case, additional input parameters such as total column ozone measurements during the day, information about the sun visibility for cloudy cases and also information on the cloud type and height can be used to improve the LM method at locations that could provide such data.

Acknowledgements. This research was funded by contract EVK2CT-2001-00130 (INSPECTRO) from the European Commission. We would like to acknowledge the UV Processing team of NASA/Goddard Space Flight Center for the provision of the TOMS UV data used in this work.

Topical Editor F. D'Andrea thanks two anonymous referees for their help in evaluating this paper.

\section{References}

Anderson, G. P., Clough, S. A., Kneizys, F. X., Chetwynd, J. H., and Shettle, E. P.: TechReport, AFGL Atmospheric Constituent Profiles (0-120 km), AFGL (OPI), AFGL-TR-86-0110, Hanscom AFB, MA 01736, 1986.

Arola, A., Kalliskota, S., den Outer, P. N., Edvardsen, K., Hansen, G., Koskela, T., Martin, T. J., Matthijsen, J., Meerkoetter, R., Peeters, P., Seckmeyer, G., Simon, P. C., Slaper, H., Taalas, P., and Verdebout, J.: Assessment of four methods to estimate surface UV radiation using satellite data, by comparison with ground measurements from four stations in Europe, J. Geophys. Res., 107(D16), 4310, doi:10.1029/2001JD000462, 2002.

Bais, A. F., Zerefos, C. S., Meleti, C., Ziomas, I. C., and Tourpali, K.: Spectral measurements of solar UVB radiation and its relations to total ozone, $\mathrm{SO}_{2}$ and clouds, J. Geophys. Res., 98, 5199-5204, 1993.

Bais, A. F., Topaloglou, C. B., Kazadzis, S., Blumthaler, M., Schreder, J., Schmalwieser, A., Henriques, D., and Janouch, M.: Report of the LAP/COST/WMO intercomparison of erythemal radiometers, WMO/GAW report No. 141, World Meteorological Organization, Geneva, 1999.

Chubarova, N. Y., Yurova, A. Y., Krotkov,. N. A., Herman, J. R., and Bhartia, P. K.: Comparison between ground measurements of UV irradiance 290 to $380 \mathrm{~nm}$ and TOMS UV estimates over Moscow for 1979 to 2000, Opt. Eng., 41(12), 3070-3081, 2002.

Cotté, H., Devaux, C., and Carlier, P.: Transformation of irradiance measurements into spectral actinic flux for photolysis rates determination, J. Atmos. Chem., 26, 1-28, 1997.

Daumont, D., Brion, J., Charbonnier, J., and Malicet, J.: Ozone UV spectroscopy. 1. Absorption cross-sections at room-temperature, J. Atmos. Chem., 15, 145-155, 1992.

De More, W., Sander, S., Golden, D., Hampson, R., Kurylo, M., Howard, C., Ravishankara, A., Kolb, C., and Molina, M.: Chemical kinetics and photochemical data for use in stratospheric modelling, JPL Publ., 97-4, 1997.

Evans, W. F. J., Fats, H., Forrester, A. J., Henderson, G. S., Kerr, J. B., Vupputuri, R. K. R., and Wardle, D. I.: Stratospheric ozone science in Canada: An agenda for research and monitoring, Environ Can., Rep ARD 87-3, 127 pp., Atmos. Environ. Serv., Dowsview, Ontario, Canada, 1987.

Fioletov, V., Kerr, J. B., Wardle, D. I., Krotkov, N., and Herman, J. R.: Comparison of Brewer ultraviolet irradiance measurements with Total Ozone Mapping Spectrometer satellite retrievals, Opt. Eng., 41(12), 3051-3061, 2002.

Fioletov, V. E., Kimlin, M. G., Krotkov, N. A., McArthur, L. J. B., Kerr, J. B., Wardle, J. B., Herman, J. R., Metltzer, R., Mathews, 
T. W., and Kaurola, J.: UV index climatology over North America from ground-based and satellite estimates, J. Geophys. Res., 109, D22308, doi:10.1029/2004JD004820, 2004.

Gantner, L., Winkler, P., and Köhler, U.: A method to derive longterm time series and trends of UV-B radiation (1968-1997) from observations at Hohenpeissenberg (Bavaria), J. Geophys. Res., 104, 4879-4888, 2000.

Herman, J. R., Krotkov, N. A., Celarier, E., Larko, D., and Labow, G.: Distribution of UV radiation at the Earth's surface from TOMS-measured UV-backscattered radiances, J. Geophys. Res., 104, 12 059-12 076, 1999.

Josefsson, W.: Solar ultraviolet radiation in Sweden, SMHI Rep. Meteorol. Climatol., Nr. 53, Swed. Meteorol. And Hydrol. Indt., Norrkoping, Sweden, 72 p., 1986.

Kalliskota, S., Kaurola, J., Taalas, P., Herman, J. R., Celarier, E., and Krotkov, N. A.: Comparison of daily UV doses estimated from Nimbus-7/TOMS measurements and ground-based spectroradiometric data, J. Geophys. Res., 105, 5059-5067, 2000.

Kazadzis, S., Bais, A. F., Balis, D., Zerefos, C. S., and Blumthaler, M.: Retrieval of down-welling UV actinic flux density spectra from spectral measurements of global and direct solar UV irradiance, J. Geophys. Res., 105, 4857-4864, 2000.

Kazadzis, S., Topaloglou, C., Bais, A. F., Blumthaler, M., Balis, D., Kazantzidis, A., and Schallhart, B.: Actinic flux and $\mathrm{O}^{1} \mathrm{D}$ photolysis frequencies retrieved from spectral of irradiance at Thessaloniki, Greece, Atmos. Chem. Phys., 4, 2215-2226, 2004, http://www.atmos-chem-phys.net/4/2215/2004/.

Kazadzis, S., Bais, A., Amiridis, V., Balis, D., Meleti, C., Kouremeti, N., Zerefos, C. S., Rapsomanikis, S., Petrakakis, M., Kelesis, A., Tzoumaka, P., and Kelektsoglou, K.: Nine years of UV aerosol optical depth measurements at Thessaloniki, Greece, Atmos. Chem. Phys., 7, 2091-2101, 2007,

http://www.atmos-chem-phys.net/7/2091/2007/.

Kazantzidis, A., Bais, A. F., Grøbner, J., Herman, J., Kazadzis, S., Krotkov, N. A., Kyrø, E., Reinen, H., den Outer, P. N., Garane, K., Görts, P., Lakkala, K., Meleti, C., Slaper, H., and Turunen, T.: Comparison of ground-based and TOMS surface UV irradiances over four stations in Europe, J. Geophys. Res., 111, D13207, doi:10.1029/2005JD006672, 2006.

Kerr, J. B. and McElroy, C. T.: Evidence for large upward trends of ultraviolet-B radiation linked to ozone depletion, Science, 262, 1032-1034, 1993.

Koukouli, M. E., Balis, D. S., Amiridis, V., Kazadzis, S., Bais, A., Nickovic, S., and Torres, O.: Aerosol variability over Thessaloniki using ground based remote sensing observations and the TOMS aerosol index, Atmos. Environ., 40, 5367-5378, 2006.

Kraus, A. and Hofzumahaus, A.: Field measurements of atmospheric photolysis frequencies for $\mathrm{O}_{3}, \mathrm{NO}_{2}, \mathrm{HCHO}, \mathrm{CH} 3 \mathrm{CHO}$, $\mathrm{H}_{2} \mathrm{O}_{2}$ and $\mathrm{HONO}$ by UV spectroradiometry, J. Atmos. Chem., 31, 161-180, 1998.

Krotkov, N. A., Herman, J. R., Bhartia, P. K., Fioletov, V., and Ahmad, A.: Satellite estimation of spectral surface UV irradiance: 2. Effects of homogeneous clouds and snow, J. Geophys. Res., 106, 11 743-11 760, 2001.

Krotkov, N. A., Herman, J. R, Bhartia, P. K., Seftor, C., Arola, A., Kaurola, J., Koskinen, L., Kalliskota, S., Taalas, P., and Geogdzhaev, I.: Version 2 TOMS UV algorithm: Problems and enhancements, Opt. Eng., 41(12), 3028-3039, 2002.

Krotkov, N. A., Bhartia, P. K., Herman, J. R., Slusser, J., Scott, G.,
Janson, G., Labow, G., Eck, T., and Holben, B.: Aerosol UV absorption experiment (2002-04): 1. UV-MFRSR calibration and intercomparison with CIMEL Sunphotometers, Opt. Eng., 44(4), 041004, 2005.

Kylling, A., Webb, A. R., Bais, A. F., Blumthaler, M., Schmitt, R., Thiel, S., Kazantzidis, A., Kift, R., Misslebeck, M., Schallhart, B., Schreder, J., Topaloglou, C., Kazadzis, S., and Rimmer, J.: Actinic flux determination from measurements of irradiance, J. Geophys. Res., 108(D16), 4506-4515, doi:10.1029/2002JD003236, 2003.

Kylling, A., Webb, A. R., Kift, R., Gobbi, G. P., Ammanato, L., Barnaba, F., Bais, A., Kazadzis, S., Wendisch, M., Jäkel, E., Schmidt, S., Kniffka, A., Thiel, S., Junkerman, W., Blumthaler, M., Silbernagl, R., Schallhart, B., Schmitt, R., Kjeldstad, B., Thorseth, T. T., Schreier, R., and Mayer, B.: Spectral actinic flux in the lower troposphere: measurement and 1-D simulations for cloud free, broken cloud and overcast situations, Atmos. Chem. Phys., 5, 1975-1997, 2005,

http://www.atmos-chem-phys.net/5/1975/2005/.

McKenzie, R., Seckmeyer, G., Bais, A. F., Kerr, J. B., and Madronich, S.: Satellite-retrievals of erythemal UV dose compared with ground-based measurements at northern and southern mid-latitudes, J. Geophys. Res., 106, 24 051-24 062, 2001.

Madronich, S.: Photodissociation in the Atmosphere: 1. Actinic Flux and the Effects of Ground Reflections and Clouds, J. Geophys. Res., 92(D8), 9740-9752, 1987.

Masson, K. and Kyrö, E.: A decade of spectral UV-B measurements in Sodankylä, Finland. European Geophysical Society 26, General Assembly 2001, EGS Newsletter, 203, 2001.

Matsumi, Y., Murakami, S., Kono, M., Takahashi, K., Koike, M., and Kondo, Y.: High-sensitive instrument for measuring atmospheric NO2, Analytical Chemistry, 73, 5485-5493, 2001.

Mayer, B., Seckmeyer, G., and Kylling, A.: Systematic longterm comparison of spectral UV measurements and UVSPEC modeling results, J. Geophys. Res., 102(D7), 8755-8768, doi:10.1029/97JD00240, 1997.

Mayer, B., Fischer, C. A., and Madronich, S.: Estimation of surface actinic flux from satellite (TOMS) ozone and cloud reflectivity measurements, Geophys. Res. Lett., 25(23), 4321-4324, doi:10.1029/1998GL900140, 1998.

Mayer, B. and Kylling, A.: Technical Note: The libRadtran software package for radiative transfer calculations: Description and examples of use, Atmos. Chem. Phys., 5, 1855-1877, 2005, http://www.atmos-chem-phys.net/5/1855/2005/.

McKenzie, R. L., Johnston, P. V., Hofzumahaus, A., Kraus, A., Madronich, S., Cantrell, C., Calvert, J., and Shetter, R.: Relationship between photolysis frequencies derived from spectroscopic measurements of actinic fluxes and irradiances during the IPMMI campaign, J. Geophys. Res., 107(D5), 4042-4057, 2002.

Schallhart, B., Huber, M., and Blumthaler, M.: Semi-empirical method for the conversion of spectral UV global irradiance data into actinic flux, Atmos. Environ., 38, 4341-4346, 2004.

Seroji, A. R., Webb, A. R., Coe, H., Monks, P. S., and Rickard, A. R.: Derivation and validation of photolysis rates of $\mathrm{O}_{3}, \mathrm{NO}_{2}$ and $\mathrm{CH}_{2} \mathrm{O}$ from a GUV-541 radiometer, J. Geophys. Res., 109, D21307, doi:10.1029/20004JD004674, 2004.

Slaper, H., Reinen, J. M. H. A., Blumthaler, M., Huber, M., and Kuik, F.: Comparing ground-level spectrally resolved solar UV measurements using various instruments: a technique resolving 
effects of wavelength shift and slit width, Geophys. Res. Lett., 22, 2721-2724, 1995.

Shettle, E. P.: Models of aerosols, clouds and precipitation for atmospheric propagation studies, in Atmospheric Propagation in the UV, Visible, IR and MM-region and Related System Aspects, AGARD Conf. Proc., 15, 1-13, 1989.

Stamnes, K., Tsay, S. C., Wiscombe, W., and Jayaweera, K.: A numerically stable algorithm for discrete-ordinate-method radiative transfer in multiple scattering and emitting layered media, Appl. Optics, 27(12), 2502-2509, 1988.

Topaloglou, C., Kazadzis, S., Bais, A. F., Blumthaler, M., Schallhart, B., and Balis, D.: $\mathrm{NO}_{2}$ and $\mathrm{HCHO}$ photolysis frequencies from irradiance measurements in Thessaloniki, Greece, Atmos. Chem. Phys., 5, 1645-1653, 2005,

http://www.atmos-chem-phys.net/5/1645/2005/.

Van Weele, M., de Arleeano, J. V.-G., and Kuik, F.: Combined measurements of UV-A actinic flux, UV-A irradiance and global radiation in relation to photodissociation rates, Tellus, Ser. B, 47, 333-364, 1995.

Vasaras, A., Bais, A. F., Feister, U., and Zerefos, C. S.: Comparison of two methods for cloud flagging of spectral UV measurements, Atmos. Res., 57/1, 31-42, 2001.
Webb, A., Bais, A. F., Blumthaler, M., Gobbi, G.-P., Kylling, A., Schmitt, R., Thiel, S., Barnaba, F., Danielsen, T., Junkermann, W., Kazantzidis, A., Kelly, P., Kift, R., Liberti, G. L., Misslbeck, M., Schallhart, B., Schreder, J., and Topaloglou, C.: Measuring spectral actinic flux and irradiance: Experimental results from the Actinic Flux Determination from Measurements of Irradiance (ADMIRA) project, J. Atmos. Oceanic Technol., 19, 10491062, 2002a.

Webb, A. R., Kift, R., Thiel, S., and Blumthaler, M.: An empirical method for the conversion of spectral UV irradiance measurements to actinic flux data, Atmos. Environ., 36, 4044-4397, $2002 b$.

WMO: Report of the WMO-WHO Meeting of Experts on Standardization of UV Indices and their Dissemination to the Public (Les Diableries, 1997), GAW Report No. 127, Genova, 1998.

Zerefos, C. S.: Long-term ozone and UV variations at Thessaloniki, Greece, Phys. Chem. Earth, 27, 455-460, 2002. 